\title{
LOS ASUNTOS NO CONTENCIOSOS DE COMPETENCIA NOTARIAL
}

\author{
NON-CONTENTIOUS PROCEDURE BEFORE A NOTARY
}

\author{
Fernando Tarazona Alvarado ${ }^{1}$ \\ Notaría Fernando Tarazona Alvarado \\ Lima, Perú \\ https://orcid.org/0000-0003-0333-6215 \\ ftarazona0311@yahoo.com
}

\begin{abstract}
RESUMEN
Este año se cumplen 25 años desde la promulgación de la Ley № 26662, norma mediante la cual se otorgaron facultades a los notarios para que puedan conocer de manera alternativa al Poder Judicial, ciertos asuntos no contenciosos, siendo ello un pedido de larga data tanto de la doctrina como de la Unión Internacional del Notariado Latino, debido a que se trata de procedimientos donde no hay litigio, y por tanto, perfectamente asumibles por los notarios debido a su función fedante, contribuyendo con ello a la descongestión del poder judicial. Diversos países de Europa, América y Asia, con presencia del notariado latino, vienen otorgando a los notarios facultades para tramitar asuntos no contenciosos, no siendo el Perú la excepción. Si bien la ley № 26662 recogió en un inicio sólo seis asuntos no contenciosos, posteriormente se fueron agregando otros, debido a la acogida que tuvo entre la población, dada la celeridad con la que se tramitan. Sin embargo, debe señalarse que aún no pasaron a la competencia notarial todos los asuntos no contenciosos donde no sea necesaria la actuación de pruebas, debiendo de producirse ello dada las ventajas que representa para la sociedad.
\end{abstract}

\section{PALABRAS CLAVES}

Asuntos no contenciosos, jurisdicción voluntaria, falta de litigio, notario, descongestión del poder judicial.

\begin{abstract}
This year marks 25 years since the enactment of Law No. 26662, a rule by which notaries were granted powers so that they can hear, alternatively, the Judiciary, certain non-contentious matters, this being a longstanding request for both the doctrine as of the International Union of Latin Notaries, due to the fact that these are procedures where there is no litigation, and therefore, perfectly acceptable by notaries due to their notarial function, thereby contributing to the decongestion of the judiciary. Various countries in Europe, America and Asia, with the presence of Latin notaries, have been granting notaries powers to process non-contentious matters, Peru being the exception. Although law No. 26662 initially collected only six non-contentious cases, later others were added, due to the reception it had among the population, given the speed with which they are processed. However, it should be noted that all non-contentious matters where evidence is not necessary have not yet passed to the notarial jurisdiction, and this must occur given the advantages it represents for society.
\end{abstract}

\section{KEYWORDS}

Non-contentious matters, voluntary jurisdiction, lack of litigation, notary, decongestion of the judiciary.

1 Notario de Lima. Abogado por la Pontificia Universidad Católica del Perú, con estudios de Maestría en Derecho Civil en dicha casa de estudios. Posgrado en Derecho Registral en la Universidad Autónoma de Madrid. Pasantía en despachos notariales de España. Ex Vocal del Tribunal Registral y ex Registrador del Registro de Propiedad Inmueble de la Oficina Registral de Lima. Autor del libro "El sistema registral peruano y los principios que lo rigen" y de artículos en materia notarial y registral publicados, en obras y revistas jurídicas. 


\section{INTRODUCCIÓN}

Este año se cumplen 25 años de la promulgación de la ley $\mathrm{N}^{\circ} 26662$, Ley de Competencia Notarial en Asuntos no Contenciosos, norma mediante la cual se otorga facultades a los notarios para que puedan conocer de manera alternativa al Poder Judicial, ciertos asuntos no contenciosos, conocidos en la doctrina como de jurisdicción voluntaria.

Al respecto, cabe destacar el equívoco del término jurisdicción voluntaria, en razón a no tratarse propiamente de una jurisdicción, al no existir conflicto de intereses, litigo o litis.

Como señala Couture, respecto a la definición de jurisdicción, es una

Función pública realizada por órganos competentes del Estado, con las formas requeridas por la ley, en virtud de la cual, por acto de juicio, se determina el derecho de las partes con el objeto de dirimir sus conflictos y controversias de relevancia jurídica, mediante decisiones con autoridad de cosa juzgada, eventualmente factibles de ejecución. (Somocurcio, 2013, p. 193).

Por su parte, para Alzamora Valdez: "La jurisdicción contenciosa, que es la verdadera jurisdicción, es la facultad que tienen los jueces de conocer los asuntos litigiosos y ejecutar sus decisiones" (Portugal, 2015, p. 10).

Tampoco es voluntaria porque, a decir de García Coni, citado por Bazet, Fiorentino y Frontini, “. ... en virtud de leyes procesales, irremediablemente se debe recurrir a los órganos jurisdiccionales y seguir sus reglas"(Portugal, 2015, p. 22).

En ese sentido, creemos que el término mas adecuado para designar a este tipo de procedimientos donde no existe litis, es el de asuntos no contenciosos, conforme se encuentra recogido en la Ley $\mathrm{N}^{\circ}$ 26662. Al respecto, en la VI Jornada Notarial Iberoamericana desarrollada en 1988, en Acapulco, se recomendó que se incluyera en las legislaciones de los notariados iberoamericanos la denominación de "procesos o procedimientos no contenciosos en sede notarial", en reemplazo del término "jurisdicción voluntaria", por estimarse inadecuada (Colegio de Notarios de Lima, 2016, p. 20).

La Ley $\mathrm{N}^{\circ}$ 26662, publicada el 22 de setiembre de 1996, entró en vigencia el 21 de noviembre de dicho mismo año, luego de 60 días de vacatio legis. Dicha ley recoge el proyecto sustitutorio elaborado por la Comisión de Justicia del Congreso de la República, el mismo que se elaboró sobre la base de cinco proyectos presentados, por diversos congresistas (Lourdes Flores Nano, Ántero Flores-Aráoz y Xavier Barrón; Javier Alva Orlandini; Jorge Avendaño Valdez; Aldo Estrada Choque; y Eugenio Vicuña), y el anteproyecto alcanzado por el Colegio de Notarios de Lima (en adelante CNL).

Cabe señalar que la tramitación de asuntos no contenciosos, o de jurisdicción voluntaria, por parte del notariado, era un pedido de larga data por parte de la doctrina, no sólo notarialista (Mengual, Vásquez Campo, Morales Díaz, Velasco, Navarro Aspeitia, García Martínez), sino también de letrados (Ossorio Gallardo) (Giménez-Arnau; 1976 p. 83), en razón a que en este tipo de procedimientos, siguiendo a Giménez Arnau, se declara hechos y situaciones jurídicas, no derechos de una manera directa; lo resuelto no goza de cosa juzgada; y no habiendo declaración de derechos controvertidos, ni posibilidad de que haya oposición, no tiene por qué intervenir el juez (GiménezArnau, 1976, p. 83). 
A lo señalado, se puede agregar que, con la asunción de los asuntos no contenciosos por parte del notariado, se pone a disposición de los ciudadanos los cientos de notarios que se encuentran repartidos a nivel nacional, acercándoseles dicho importante servicio público, a la vez que se aligera la carga procesal que existe actualmente en los juzgados, permitiendo a los jueces concentrarse en la resolución de los asuntos contenciosos, que son de su exclusiva competencia. Como señala Becerra Palomino,

... creemos que la frase de Joaquín Costa: "notaría abierta, juzgado cerrado", que en cierto modo puede interpretarse como restrictiva del derecho de acción, podría muy bien ser reemplazada por la frase "notaría abierta, juzgado descongestionado"; para destacar la labor encomendada a los notarios en la tramitación de los asuntos que no contienen litis. (Becerra Palomino, 2015, p.170).

La Unión Internacional del Notariado (UINL), organización internacional que agrupa a los notariados de tipo latino del mundo, por su parte, a través de sus diversos congresos internacionales, señaló la conveniencia que los asuntos no contenciosos pasen a la competencia del notariado. Así, tenemos, en su primer Congreso Internacional, desarrollado en Buenos Aires, en 1948, se concluyó que la jurisdicción voluntaria debía ser incluida dentro de la función notarial, pues en todos estos procedimientos en el que el juez no ejercía imperio, no había razón para que queden entrampados en la Corte (CNL, 2016, p. 18). En el II Congreso Internacional, desarrollado en Madrid, en el año 1950, se señaló que debía aplicarse el acta de notoriedad en diversos asuntos como en el caso de declaratoria de herederos, entre otros (Portugal, 201, p. 39). En el IV Congreso Internacional, celebrado en 1956, en Río de Janeiro, se insistió en la conveniencia de la intervención notarial en los asuntos no litigiosos, recomendándose la creación de un Registro internacional de testamentos y la participación notarial en las sucesiones sin contienda (CNL, 2016, p. 19). En el VI Congreso Internacional, celebrado en 1965, se propuso como competencia notarial los siguientes asuntos: la rectificación de partidas en el Registro Civil; la inscripción tardía de nacimientos; la declaración de identidad de las personas; la mensura, deslinde y amojonamiento de terrenos; la apertura de testamentos cerrados; la protocolización de testamentos cerrados; los procedimientos sucesorios; el discernimiento de la tutela y curatela; la adopción de menores; la cautela de los bienes de menores; y la autorización para el matrimonio de personas no adultas (CNL, 2016, p. 20). En el VIII Congreso Internacional, desarrollado en México, en 1965, se indicó lo inapropiado que resultaba la denominación de jurisdicción voluntaria y que se debería de incluir como parte de la función notarial las situaciones que importen la comprobación y autenticación de hechos (Portugal, 2016, p. 39). En el XII Congreso Internacional, llevado a cabo en 1973, en Buenos Aires, se solicitó a los países miembros de la Unión, que realicen todas las acciones y pongan especial esfuerzo para que en sus legislaciones internas se pueda incluir diversos temas dentro de la función notarial, poniéndose énfasis en los de carácter familiar, como la reconciliación matrimonial, lo concerniente a acuerdos adoptados de manera previa al divorcio, el cuidado de los hijos menores de edad y el régimen de bienes de menores en lo concerniente a su cuidado y administración (Portugal, 2015, p. 39). Por último, en el XVI Congreso Internacional, celebrado en Lima, en el año 1982, se señala que en las actas de notoriedad en las que interviene el notario, no se requiere la intervención ni posterior aprobación judicial ni de ninguna otra autoridad (Portugal, 2015, p. 38-40).

Debe señalarse que, si bien históricamente se encargó al Poder Judicial la resolución de los asuntos no contenciosos o de jurisdicción voluntaria, al tratarse de procedimientos donde no hay litigio, perfectamente podían ser tramitados ante los notarios, al gozar éstos de fe pública. Es mas, sería un regreso de dicha función a los notarios, ya que en los siglos XI y XII, los notarios tuvieron a su cargo las actuaciones que reemplazaron los denominados juicios aparentes o fingidos (jurisdicción 
voluntaria), pero que lo fueron perdiendo con el correr del tiempo, siendo asumidos por el Poder Judicial. Como señala Couture,

La jurisdicción voluntaria perteneció en sus primeros tiempos a los notarios, y con el andar del tiempo fue pasando a los órganos del poder judicial; nada impide que pasen mañana a la administración y aunque vuelvan a su fuente de origen, como se ha propuesto. (Portugal, 2015, p. 35).

\section{LEGISLACIÓN COMPARADA}

Respecto a la legislación comparada, tenemos que los notarios tramitan los siguientes asuntos no contenciosos:

\section{Europa:}

Alemania: En el artículo 20-3 de su legislación notarial, se delimitan lo siguientes asuntos de jurisdicción no contenciosa: ventas en subastas libres; contrato matrimonial; declaración de consentimiento a la adopción; contrato de herencia; mediación en particiones sucesorias o de comunidades (Cárdenas, 2014, pp. 121-122).

Austria: El notario tiene competencia para: recibir documentos privados; representar a los particulares ante las autoridades administrativas en cuestiones legales no contenciosas e incluso en procedimientos ejecutivos judiciales; intervenir como comisario judicial en la apertura de sucesión, venta en subasta de bienes inmuebles o muebles, formalización de inventarios y redacción o examen de cuentas o propuesta de división de un patrimonio; adopción de menores y de menores emancipados; divorcio de común acuerdo; apertura de testamento cerrado y protocolización de testamento ológrafo; contratos de matrimonio; donaciones sin desposesión real; ciertos contratos entre esposos; contratos hereditarios; contrato relativo a la renuncia anticipada de una sucesión; inventario de herencia; unión de hecho o unión libre; y legalización de libros de personas jurídicas, entidades y asociaciones de comerciantes (Cárdenas, 2014, p. 122).

Bélgica: La competencia notarial en el ámbito de la jurisdicción no contenciosa se regula por la Ley del Ventoso, contemplándose los siguientes asuntos: adopciones; divorcio cuando hay adjudicación de bienes; inventario; partición judicial derivada de una sucesión o de una liquidación de régimen matrimonial; embargo y ejecución forzada; y ventas públicas de inmuebles (Cárdenas, 2014, pp. 122-123).

Francia: Conforme con la Ley de Ventoso de 1803, el notario tiene competencia para: el levantamiento de embargos o trabas; convenciones entre esposos durante la instancia de divorcio para la liquidación y partición de los bienes comunes; y la declaración de herederos ab intestato sin limitación por razón de parentesco (Cárdenas, 2014, p. 124).

España: En el año 2015 se aprobó la Ley 15/2015, Ley de Jurisdicción Voluntaria, donde se otorga competencias a los notarios en: la declaratoria de herederos; matrimonio; separación y divorcio; adveración del testamento ológrafo; procedimiento de obtención de ejecutividad del crédito; constancia del régimen económico matrimonial; y competencia en expedientes sucesorios.

Italia: Los notarios italianos pueden intervenir en los siguientes asuntos no contenciosos: intervenir en todos los actos y contratos intervivos o mortis causa, sin excepción, que celebren los 
particulares y a los que quieran dar el carácter de documento público; suscribir y presentar recursos relativos a los actos de jurisdicción graciosa, en lo referente a las estipulaciones de cada una de las partes; intervenir por delegación de la autoridad judicial en la colocación y remoción de sellos en los casos previstos en las leyes civiles y comerciales, inventarios en materia civil y comercial, subastas, divisiones judiciales y todas las operaciones necesarias para ello, y expedición de certificados de vida a los pensionistas y a los demás beneficiarios del Estado; actuar con funciones de jueces honorarios adjuntos en juicios y procedimientos civiles; ventas en subasta voluntaria; ventas en subasta de bienes muebles dados en prenda; y legalización de libros de las personas jurídicas (Cárdenas, 2014, pp. 124-126).

\section{América:}

Guatemala: A propósito de la inauguración del XIV Congreso Internacional del Notariado Latino, en el año 1977, el presidente de la República de dicho país aprobó el decreto 54-77, Ley reguladora de la tramitación notarial de los asuntos de jurisdicción voluntaria, siendo el primer antecedente en América en cuanto a la tramitación de los asuntos no contenciosos por parte del notariado (CNL, 2016, p. 21-22), facultándose a los notarios la tramitación en sede notarial de: la declaración de ausencia; la disposición y gravamen de bienes de menores, incapaces y ausentes; el reconocimiento de preñez o de parto; el cambio de nombre; el asiento extemporáneo de partidas y actas del Registro Civil -nacimiento, defunción, matrimonio y otras; la determinación de edad; la constitución de patrimonio familiar; y la rectificación de área, esta última en mérito al Decreto Ley 125-83.

Brasil: En mérito a la Ley $N^{\circ} 11.441 / 2007$, los notarios tienen competencia sobre los siguientes asuntos no contenciosos: inventario y reparto en sucesiones testamentarias cuando todos los herederos son capaces; y separación consensual y divorcio ulterior consensual por vía administrativa, no habiendo hijos menores o incapaces y siempre que hayan transcurrido 2 años de una separación de hecho de la pareja (Cárdenas, 2014, p. 115).

Bolivia: Con la Ley $\mathrm{N}^{\circ} 483$, del 25 de enero de 2014, se otorga competencia notarial para intervenir en los trámites de: retención o recuperación de la posesión de bienes inmuebles; deslinde y amojonamiento de predios urbanos; divisiones y particiones inmobiliarias, aclaración de límites de medianerías; procesos sucesorios sin testamento; división y partición de herencias; apertura de testamento cerrado; divorcio de mutuo acuerdo; permisos de viajes al exterior de menores; nombramiento de tutor y curador de persona mayor de edad; adopción de persona mayor de edad; autorización para el matrimonio de persona menor de edad; aceptación expresa o renuncia de herencia; y emancipación.

Costa Rica: En el Código Notarial (Ley 7764), se otorga competencia notarial en: los procedimientos de liquidación de sociedades mercantiles; sucesiones; adopciones; localizaciones de derechos indivisos; informaciones de perpetua memoria; divisiones de cosas comunes; distribución del precio; deslindes y amojonamientos; consignaciones de pagos de sumas de dinero; y remates de garantías mobiliarias.

EI Salvador: Mediante la Ley del Ejercicio Notarial de la Jurisdicción Voluntaria y otras Diligencias, de 1982, se otorgó competencias a los notarios para la tramitación de los siguientes procedimientos: ausencia de padre o madre que debe dar su consentimiento para el matrimonio de un menor de edad; omisiones o errores en certificaciones de partidas del registro del estado familiar; establecimiento subsidiario de un estado familiar o de la muerte de una persona; deslinde voluntario; remedición 
de inmuebles; títulos supletorios; apertura y publicación de testamentos cerrados; aceptación de herencia; y adopción.

Canadá: Las facultades de los notarios para intervenir en asuntos no contenciosos se regula en el Libro Sexto de su legislación de procedimiento civil, bajo el rubro de "leyes o contenciosas", siendo éstos los siguientes: requerimientos relativos a tutelas nombradas; nombramiento de tutor del menor; procedimiento para la apertura o revisión de un régimen de protección de los mayores de edad; poder en previsión de ineptitud; y alteración de testamento (Cárdenas, 2014, p. 115).

Ecuador: En mérito a la Ley reformatoria a la Ley Notarial (1996 y 2006), los notarios ejercen los siguientes actos de jurisdicción voluntaria: disolución de la sociedad conyugal; extinción o subrogación del patrimonio familiar; posesión efectiva de bienes pro indiviso de los bienes del causante; divorcio por mutuo consentimiento; autorización de actos de amojonamiento y deslinde en sectores rurales; liquidación de bienes o de la sociedad conyugal; apertura y publicación de testamentos cerrados; petición de declaratoria de interdicción (López, 2014, pp. 62-68).

Honduras: Con el Decreto $\mathrm{N}^{\circ} 353-2005$, se otorga facultades a los notarios para que puedan conocer los siguientes procedimientos: rectificación de inscripciones en el Registro Civil; patrimonio familiar; habilitación para comparecer en juicio; emancipación voluntaria; habilitación de edad; información ad-perpetuam; divorcio por mutuo consentimiento; inventarios solemnes; separación de hecho; conciliación y arbitraje; ejecución de garantías; autorización para contraer segundas y ulteriores nupcias; autorización para enajenar bienes menores; deslinde y amojonamiento; celebración de matrimonios; calificación de edad; cesación de comunidad; partición de bienes; y requerimientos de pagos.

Colombia: Mediante la Ley $N^{\circ} 982$ del 8 de julio de 2005, se dio competencia a los notarios para que conozcan los siguientes asuntos: cesación de los efectos civiles de todos los matrimonios religiosos reconocidos por el Estado colombiano; divorcio del matrimonio civil; constitución de patrimonio de familia inembargable; celebración de capitulaciones; constitución, disolución y liquidación de sociedad patrimonial entre compañeros permanentes; matrimonio civil; e inventario de bienes de menores que se encuentren bajo patria potestad cuando los padres estén administrándolos y quieran contraer matrimonio (Echeverri, 2014, p. 40).

México: Los notarios mexicanos conocen los siguientes asuntos no contenciosos: sucesiones testamentarias, en caso del testamento público abierto, e intestamentarias; en caso no hubiere menores emancipados o mayores incapacitados, constitución, modificación y extinción del patrimonio familiar voluntario, diligencias de apeo y deslinde, las informaciones ad perpetuam cuando se trate de justificar algún hecho o acreditar un derecho o de justificar la posesión como medio para acreditar el dominio pleno de un mueble (excepto las informaciones de dominio de bienes inmuebles); declaración del estado de minoridad y nombramientos de tutores y curadores, exclusivamente para la tramitación extrajudicial de sucesiones testamentarias o legítimas, y sólo tratándose de menores de edad; y arbitraje y mediación notarial (Cárdenas, 2014, pp. 118-119).

\section{Asia:}

China: Conforme a lo expresado por el presidente del Sector Asia de la UINL y también presidente de China Notary Association, Duan Zhengkun, los notarios tienen competencia sobre sucesiones testamentarias y ab intestato (Lanzón y Massa, 2014, p. 17). 


\section{LOS ASUNTOS NO CONTENCIOSOS DE COMPETENCIA NOTARIAL EN EL PERÚ}

Con la Ley $\mathrm{N}^{\circ} 26662$, se facultó a los notarios a conocer, en principio, seis asuntos no contenciosos, cuales son: rectificación de partidas, adopción de personas capaces, patrimonio familiar, inventarios, comprobación de testamentos y sucesión intestada.

La competencia notarial se estableció, como se señaló, de manera alternativa al Poder Judicial, es decir, este órgano del Estado siguió manteniendo competencia sobre dichos asuntos no contenciosos; sin embargo, los ciudadanos en su gran mayoría optaron por tramitar dichos asuntos no contenciosos en sede notarial, a pesar, incluso, de su aparente mayor costo -lo que es relativo porque muchas veces la demora en el tramite acarrea al final un mayor costo al ciudadano-, contribuyendo a la descongestión de la carga procesal en los juzgados. Como dijera Couture, "el tiempo es más que oro, es justicia" (Becerra Palomino, 2015, p. 170).

En razón a la buena acogida que tuvo en la ciudadanía la asignación de competencias notariales sobre dichos asuntos no contenciosos, se fueron adicionando mas asuntos de jurisdicción voluntaria bajo la competencia de los notarios, según se señala a continuación:

- Mediante la Ley $\mathrm{N}^{\circ}$ 27157, su reglamento aprobado (Decreto Supremo $\mathrm{N}^{\circ}$ 035-2006-VIVIENDA), y la Ley $\mathrm{N}^{\circ} 27333$, se facultó a los notarios para la tramitación de prescripciones adquisitivas de dominio, títulos supletorios, y rectificación de área, linderos y medidas perimétricas, sobre bienes inmuebles ubicados en zona urbana.

- Con la expedición de la Ley № 28325 y el Decreto Supremo № 012-2006-JUS, se estableció competencia notarial para la tramitación de solicitudes de prescripciones adquisitivas de dominio de vehículos automotores.

- Con Ley N 29227 y su reglamento, aprobado mediante Decreto Supremo N009-2008JUS, se facultó a los notarios, de manera alternativa a las municipalidades provinciales y distritales, a tener competencia sobre el procedimiento de separación convencional y divorcio ulterior.

- Con la Ley $N^{\circ} 29560$ se facultó a los notarios a conocer de manera alternativa al Poder Judicial el procedimiento de reconocimiento de unión de hecho, la convocatoria a junta obligatoria anual y la convocatoria a junta general.

- Mediante el Decreto Legislativo $N^{\circ} 1310$, modificado por el Decreto Legislativo $N^{\circ} 1417$, se reguló la designación, ante notario, de apoyos para las personas adultas mayores para el cobro de pensiones, devoluciones de aportes económicos o subvenciones de programas nacionales de asistencia no contributivos.

- Con la expedición de la Ley N 30933, se reguló el procedimiento especial de desalojo con intervención notarial, donde se da competencia a los notarios para la constatación de las causales de desalojo por vencimiento del contrato de arrendamiento y por falta de pago de la renta convenida.

Existen, por cierto, asuntos no contenciosos que aún no pasaron a la competencia de los notarios, las que deberían de serles otorgadas de manera alternativa, dada la eficacia demostrada por el notariado en la tramitación de dichos asuntos sometidos bajo su competencia, en todos estos años, 
donde brindaron solución a los diversos procedimientos no litigiosos, al resolverlos en plazos cortos y a precios razonables, contribuyendo con ello a la paz social.

Así, tenemos que podría otorgarse competencia a los notarios para intervenir en los siguientes asuntos no contenciosos: celebración del matrimonio civil, existiendo actualmente en el Congreso de la República un proyecto de ley en ese sentido, el proyecto de Ley $N^{\circ} 74 / 2016-C R$, que cuenta con dictámenes favorables de la Comisión de Justicia y Derechos Humanos, y de la Comisión Mujer y Familia; la inclusión de herederos preteridos en la declaratoria de sucesión intestada, debido a que por diversas circunstancias no los habían consignado en la solicitud presentada, siendo que actualmente tienen que recurrir a la vía juridicial, con el gasto de tiempo y dinero que ello implica; la administración de bienes; la declaración de desaparición, ausencia o muerte presunta; el ofrecimiento de pago y consignación; y demás asuntos no contenciosos contemplados en al Sexta Disposición Complementaria y Final del Código Procesal Civil, en la medida, claro está, que no exista una instancia de pruebas, al ser ésta propia de la función jurisdiccional.

\section{CARACTERES GENERALES DE LOS ASUNTOS NO CONTENCIOSOS}

Todos los asuntos no contenciosos de competencia notarial requieren cumplir con los siguientes requisitos, conforme se desprende de las disposiciones generales de la Ley $\mathrm{N}^{\circ} 26662$ :

\section{a) Presentación de solicitud escrita por parte de los interesados con firma de abogado}

Los asuntos no contenciosos no se inician de oficio, sino que requieren de la rogatoria por escrito de los interesados, los que pueden presentar su solicitud directamente o por medio de un representante, pudiendo ser este último voluntario o legal. En el caso de la representación legal, atendiendo a la modificación introducida por el Decreto Legislativo $\mathrm{N}^{\circ} 1384$, ésta recae en los padres o tutores de los menores de edad, y en los curadores de los pródigos, los que incurren en mala gestión, los ebrios habituales, los toxicómanos y lo que sufren pena que lleva anexa la interdicción civil.

En dicha solicitud se debe indicar el nombre del solicitante, su identificación, la dirección de todos los interesados, el motivo de la solicitud, el derecho que les asiste, el fundamento legal, la misma que debe de estar firmada por abogado.

Debe señalarse, sin embargo, que no siempre se presenta una solicitud para iniciar un asunto no contencioso, ya que en algunos casos se contempla el ingreso de una minuta, al contener la misma un negocio jurídico, como sucede en los asuntos no contenciosos de adopción de personas capaces y patrimonio familiar.

Si bien existe la obligación que la solicitud sea presentada por una de las personas legitimadas, debiendo el notario de verificar ello, sin embargo, no da fe de identidad ni de conocimiento del requirente, ni emite los juicios de capacidad, libertad y conocimiento, porque para declarar el derecho solicitado sólo necesita evaluar los instrumentos presentados, la misma que la extiende en el acta correspondiente, salvo que dicha solicitud contenga un negocio jurídico, es decir, una declaración de voluntad, como sucede en la declaración de la unión de hecho, en cuyo caso el notario procede a extender una escritura pública; a diferencia de lo que ocurre cuando se presenta una minuta, en donde se está frente a un negocio jurídico, y por lo tanto, al elevarlo a escritura pública, y al recoger la misma declaraciones de voluntad, el notario si debe de dar fe de identidad o de conocimiento de los intervinientes, y de emitir los juicios de capacidad, libertad y conocimiento del acto realizado. 
Existe la posibilidad que en la formulación de la solicitud, o minuta, del asunto no contencioso, los interesados equivoquen el fundamento legal, en cuyo caso cabe preguntarse si el notario podría aplicar la noma correcta de manera similar a como lo realizan los jueces (principio iura novit curia). Al respecto creemos que no existe ningún inconveniente en que el notario invoque la norma correcta, porque el principio iura novit curia se encuentra contemplado en el numeral VII del Título Preliminar del Código Civil. Si bien conforme al artículo 2 de la Ley $N^{\circ} 26662$, en la tramitación de los asuntos no contenciosos los notarios deben aplicar en primer lugar dicha ley, en segundo lugar el Decreto Legislativo 1049, Decreto Legislativo del Notariado, y en tercer lugar el Código Procesal Civil, sin embargo, debe tenerse en cuenta que conforme al artículo IX del Título Preliminar del Código Civil, las disposiciones del código sustantivo se aplican supletoriamente a las relaciones y situaciones jurídicas reguladas en otras leyes, siempre que no sean incompatibles con su naturaleza, siendo que en el presente caso la aplicación correcta de la norma no afecta la naturaleza del asunto no contencioso, al contrario, conlleva a declarar el derecho solicitado.

Por último, debe señalarse que no sólo deben contar con firma de abogado las solicitudes de inicio del trámite, sino también los escritos que se presenten dentro del mismo, conforme se señala en el artículo 14 de la Ley $N^{\circ} 26662$.

\section{b) Falta de litis}

Constituye requisito esencial para que el notario tenga competencia el que no exista contención o litis, es decir, que alguno de los interesados no se oponga a que el notario resuelva el asunto no contencioso sometido a su consideración.

Al respecto, en el artículo 6 de la Ley N²6662 se indica que constituye requisito indispensable para la tramitación de los asuntos no contenciosos, el que exista consentimiento unánime de los interesados, siendo que en el caso que alguna de dichas personas se oponga a que el notario resuelva el asunto no contencioso, éste debe suspender el procedimiento y remitir lo actuado al juez correspondiente, bajo responsabilidad, con excepción de los procedimientos de prescripción adquisitiva de dominio y títulos supletorios, en donde el notario da por finalizado el trámite, comunicando dicha situación al solicitante, al Colegio de Notarios y a la oficina registral correspondiente, conforme se establece en el inciso g) del artículo 5 de la Ley $\mathrm{N}^{\circ} 27333$.

Debe señalarse, sin embargo, que en la mayoría de los procedimientos no contenciosos no se requiere del consentimiento unánime de los interesados, sino de la falta de oposición de éstos. Así, tenemos que con la excepción de la adopción de persona capaz, y de la separación convencional y divorcio ulterior, donde se requiere el consentimiento de todos los interesados al inicio del trámite, en los demás procedimientos no contenciosos no se requiere de dicho consentimiento unánime, bastando con que la solicitud sea presentada por uno de los interesados, siendo en dicho supuesto necesaria la notificación y/o publicación para efectos que los demás interesados tomen conocimiento del inicio del procedimiento y de esta manera se puedan oponer en caso de considerarlo necesario.

Como se señaló, en caso de oposición, el notario suspende inmediatamente su actuación y lo remite al Poder Judicial, bajo responsabilidad, para que el juez lo resuelva. Debe señalarse que el notario no se encuentra facultado para evaluar la procedencia de dicha oposición (legitimación, fundamento o presentación dentro del plazo), porque son aspectos propios de la jurisdicción (resolución de conflicto de intereses), y, por tanto, ajenos a la función notarial. 
Coincidimos con Becerra Palomino en el sentido que lo mas conveniente hubiera sido, en caso de oposición a la continuación del asunto no contencioso, que el notario de por finalizado el tramite, dejando a salvo el derecho de los interesados de recurrir al Poder Judicial, como establece la Ley $\mathrm{N}^{\circ} 27333$ para los casos de prescripción adquisitiva de dominio y títulos supletorios, en lugar que el notario remita lo actuado al Poder Judicial, porque en los hechos se convierte en impulsor del proceso, no quedando claro quien es el juez competente (Becerra Palomino, 2015, pp. 178-179).

\section{c) Publicación}

Gran parte de los asuntos no contenciosos requieren de publicación del procedimiento, para efectos que terceros interesados tomen conocimiento $y$, eventualmente, puedan oponerse a su continuación.

Dichas publicaciones se realizan por una sola vez en el diario oficial El Peruano y en otro de amplia circulación del lugar donde se realiza el trámite, siendo que, a falta de diario en dicho lugar, se realizan en el de la localidad mas próxima, cabiendo la posibilidad de hacerlo a través de radiodifusión (artículo 169 del Código Procesal Civil). Respecto a la tramitación de asuntos no contenciosos en el interior del país, debe entenderse que las publicaciones se llevan a cabo en el diario encargado de los avisos judiciales y no en el diario oficial El Peruano.

En el caso de los asuntos no contenciosos de prescripción adquisitiva de dominio y de títulos supletorios, se hacen tres publicaciones, con intervalos de tres días, en el diario Oficial El Peruano o en el diario autorizado a publicar los avisos judiciales, y en un diario de circulación nacional, según se establece en el inciso c) del artículo 5 de la Ley $N^{\circ} 27333$.

El aviso de publicación debe contener el nombre y la dirección del notario ante quien se hace el trámite.

\section{d) Colaboración de las autoridades}

Los notarios pueden solicitar a los organismos públicos la información requerida que resulte indispensable para la tramitación de los asuntos no contenciosos, estando los funcionarios pertinentes obligados a remitir dicha información, bajo responsabilidad, conforme se establece en el artículo 7 de la Ley N²6662.

Dicha disposición debe entenderse en el sentido que el notario puede solicitar información para corroborar los instrumentos públicos alcanzados por los interesados, y no para solicitar la presentación de dichos documentos, porque es el interesado quien debe de adjuntarlos al momento de presentar la solicitud o la minuta, conforme se establece en cada procedimiento en particular.

De esta manera, los notarios podrán solicitar al Registro Nacional de Identificación y Estado Civil (RENIEC) o al Registro Civil de la municipalidad respectiva -en caso aun no haya pasado al RENIEC-, información referida a la partida de nacimiento alcanzada por el interesado para el trámite de sucesión intestada, y, de esta manera, verificar si es verdadera; o a la Municipalidad respectiva, para verificar si efectivamente visó el plano perimétrico-ubicación del inmueble, adjuntado por el interesado para un trámite de prescripción adquisitiva de dominio. 


\section{e) Extensión en escritura pública o en acta notarial}

Los asuntos no contenciosos tramitados en sede notarial concluyen en escritura pública o en acta, dependiendo, en principio, de la naturaleza del trámite.

Así, tenemos que cuando se recogen negocios jurídicos o declaraciones de voluntad, el instrumento será la escritura pública, como sucede con los casos de adopción de personas capaces, patrimonio familiar y reconocimiento de unión de hecho. En cambio, cuando el notario declara el derecho en base a los instrumentos presentados por el interesado, el documento a extender será el acta, como sucede en los asuntos no contenciosos de inventarios, comprobación de testamentos y sucesión intestada.

Existen, sin embargo, excepciones a la regla establecida, porque hay asuntos no contenciosos donde al final el notario extiende todo lo actuado en escritura pública, a pesar de no haberse presentado minuta o no contener la solicitud un negocio jurídico, sino peticiones de declaraciones de derechos en base a la presentación de instrumentos, como sucede en los casos de rectificación de partidas, prescripción adquisitiva de dominio y títulos supletorios.

El resultado de ello es la desnaturalización de la escritura pública, instrumento notarial diseñado para recoger negocios jurídicos, es decir, declaraciones de voluntad; a diferencia del acta, que es el instrumento notarial apropiado para recoger constataciones realizadas por el notario, y en el caso de los asuntos no contenciosos, sus declaraciones del derecho luego de la evaluación de lo peticionado y de los instrumentos alcanzados.

El contemplar elevar a escritura pública actuaciones donde no existen declaraciones de voluntad, sino pedidos de declaraciones de derecho en base a instrumentos alcanzados, conlleva a su necesaria desnaturalización, porque fuerza su estructura para que contenga actuaciones distintas a las establecidas en el Decreto Legislativo $\mathrm{N}^{\circ} 1049$, conforme se puede apreciar en los asuntos antes mencionados, donde en el cuerpo de la escritura pública no se consigna el negocio jurídico, recogido en minuta o no, sino la solicitud, y en la conclusión, no se plasman los extremos referidos en el artículo 59 del Decreto Legislativo 1049, sino la declaración notarial de rectificación de partida, de propiedad por prescripción adquisitiva de dominio o de título supletorio.

\section{f) Extensión de la escritura y del acta en el Registro de Asuntos No Contenciosos}

Con la Ley $N^{\circ} 26662$ se creo un nuevo registro protocolar, el Registro de Asuntos No Contenciosos, en el cual se extienden las escrituras, las actas y las protocolizaciones referidas a asuntos no contenciosos, conforme se establece en su primera disposición complementaria.

Siendo que en un mismo registro se extenderán escrituras y actas, para efectos de la numeración cronológica y sucesiva al que se refiere el artículo 45 del Decreto Legislativo $\mathrm{N}^{\circ} 1049$, coincidimos con Becerra Palomino en el sentido que debiera de utilizarse la palabra instrumento para efectos de uniformizar la terminología y numeración de las escrituras y actas que se extiendan en dicho registro (Becerrra Palomino, 2015, p. 180).

\section{g) Validez del instrumento notarial}

El artículo 12 de la Ley $N^{\circ} 26662$ señala que el documento notarial, se entiende la escritura y el acta extendida en el procedimiento no contencioso de competencia notarial, es auténtico y produce todos sus efectos, mientras no se rectifique o se declare judicialmente su invalidez. 
En concordancia con dicha disposición, se presume la validez del instrumento notarial, de manera similar como se presume la validez de los instrumentos judiciales (artículo 2011 del Código Civil) y administrativos (artículo 9 del TUO de la Ley $\mathrm{N}^{\circ} 27444$ ), no pudiendo, en consecuencia, ser observados por las instancias registrales por defectos de validez, al implicar una modificación del artículo 2011 del Código Civil, respecto a la calificación de los partes notariales.

En ese sentido, la Superintendencia Nacional de los Registros Públicos (SUNARP) aprobó la Directiva N 013-2003-SUNARP/SN, mediante la Resolución N 490-2003-SUNARP-SN, donde estableció, en relación de los asuntos no contenciosos de prescripción adquisitiva de dominio, título supletorio y saneamiento de área, linderos y medidas perimétricas, que "No será materia de calificación la validez de los actos procedimentales que, en virtud de lo previsto en la Ley $\mathrm{N}^{\circ}$ 27333 y normas complementarias, son de competencia del Notario, ni el fondo o motivación de la declaración notarial"; y el Tribunal Registral aprobó, en su CXV Pleno, desarrollado el 12 y 13 de diciembre de 2013 el siguiente acuerdo: "No corresponde a las instancias registrales calificar la validez de los actos procedimentales ni el fondo o motivación de la declaración notarial, en los títulos referidos a los asuntos no contenciosos de competencia notarial".

\section{h) Responsabilidad de los notarios}

Los notarios son responsables de la debida tramitación de los asuntos no contenciosos, debiendo de abstenerse de autorizar instrumentos contrarios a normas de orden público (artículo 4 de la Ley $\mathrm{N}^{\circ}$ 26662), disposición que guarda concordancia con la calificación de la legalidad a cargo del notario, conforme se desprende del inciso d) del artículo 19 del Decreto Legislativo $\mathrm{N}^{\circ}$ 1049; mas aún, como se vio en el acápite anterior, teniendo en cuenta que se presume la validez del instrumento notarial, y por tanto, no puede ser materia de calificación, en cuanto al procedimiento ni en el fondo, por las instancias registrales.

De esta manera, el notario debe verificar que la solicitud, o minuta, contenga los requisitos exigidos, que lo soliciten las personas legitimadas, que se presenten los instrumentos requeridos, que se realice la tramitación en la forma exigida, notificando y realizando las publicaciones en los casos contemplados, y expidiendo la escritura y el acta luego de cumplido el procedimiento, y luego de los plazos requeridos, sin que haya habido oposición por parte de algún interesado.

Por aplicación supletoria del inciso d) del artículo 19 del Decreto Legislativo $N^{\circ} 1049$, el notario podrá abstenerse de tramitar asuntos no contenciosos contrarios a la moral, a las buenas costumbres, cuando se le cause agravio personal o profesional, y podrá abstenerse de emitir traslados de la escritura pública, o del acta, cuando no se le haya sufragado los honorarios profesionales y gastos, en la oportunidad y forma convenida.

\section{CONCLUSIONES}

1. Como conclusión, se puede señalar que en estos últimos 25 años, desde la entrada en vigencia de la Ley $N^{\circ} 26662$, la sociedad se vio beneficiada de la actuación notarial en los asuntos no contenciosos, acercándoles, por un lado, dicho importante servicio público, al poner a su disposición los cientos de notarios que se encuentran repartidos a nivel nacional, de manera alternativa al Poder Judicial, competencia que tuvo buena recepción a tal punto que se fueron añadiendo más competencias notariales a las inicialmente contemplados; y por el otro, contribuyendo eficazmente a la descongestión de dicho poder 
del Estado, permitiendo que se dedican a resolver los asuntos contenciosos, del cual gozan de jurisdicción exclusiva.

2. Dicha competencia notarial sobre los asuntos no contenciosos, conocidos también como de jurisdicción voluntaria, constituía un pedido de larga data por parte de la doctrina como de la UINL, manifestada esta última a través de sus diversos congresos y foros internacionales, atendiendo a la falta de litis de este tipo de procedimientos y a la función fedante de la que gozan los notarios, competencia que, además, la tuvieron en un inicio pero que poco a poco la fueron perdiendo, siendo asumidos por el Poder Judicial.

3. De esta manera, nuestro país se enmarca dentro de la corriente mundial de asunción de competencias notariales sobre los asuntos no contenciosos, siendo necesario que dicha competencia se extienda a todos aquellos donde no exista litis, dado los claros beneficios que ello trae a la sociedad.

\section{REFERENCIAS}

- Becerra Palomino, Carlos Enrique (2015). El honor de dar fe. Ensayos de Derecho Notarial. Editorial Jurídica del Perú.

- Cárdenas Gonzáles, Fernando Antonio (2014). Competencia Notarial en Asuntos no Contenciosos. Jurisdicción Voluntaria en Iberoamérica. Gaceta Notarial.

- Colegio de Notarios de Lima - CNL (2016). 20 años de vigencia de la Ley 26662 de Competencia Notarial de Asuntos no Contenciosos. Fondo editorial del Colegio de Notarios de Lima.

- Echeverri Mesa, Ana Catalina (2014). La Jurisdicción Voluntaria en Colombia. Jurisdicción Voluntaria en Iberoamérica. Gaceta Notarial.

- Giménez-Arnau, Enrique (1976). Derecho Notarial. Ediciones Universidad de Navarra, S.A.

- Lanzón, Patricia Adriana y Massa, María Evelina (2014). Competencia Notarial en Asuntos no Contenciosos. Jurisdicción Voluntaria en Iberoamérica. Gaceta Notarial.

- López Obando, Homero (2014). La Jurisdicción Voluntaria en el Notariado Latino. Jurisdicción Voluntaria en Iberoamérica. Gaceta Notarial.

- Portugal Montejo, Mercedes (2015). Procesos No Contenciosos o Jurisdicción Voluntaria. Gaceta Notarial.

- Somocurcio Alarcón, Carlos Andrés (2013). La jurisdicción voluntaria en sede notarial. El desarrollo en el Perú. Escritos sobre Derecho Notarial. Libro homenaje a Carlos Enrique Becerra Palomino. Gaceta Notarial.

Fecha de recepción : 18 de octubre de 2021

Fecha de aceptación : 7 de noviembre de 2021 